\title{
Construção de escala para mensuração de imagem corporativa: o caso de instituição privada de ensino superior
}

\section{Construction scale for measuring corporate image: the case of private institution of higher education}

\author{
Paulo Roberto da Costa Vieira ${ }^{1}$ \\ Angelo Roberto Calderaro de Angeli ${ }^{2}$ \\ Jorge Augusto de Sá Brito e Freitas ${ }^{3}$ \\ Antônio Carlos Magalhães da Silva ${ }^{4}$
}

\section{Resumo}

A imagem corporativa funciona como interface entre a realidade exterior e o indivíduo, permitindo-lhe abstrair e simplificar conteúdos complexos sobre a organização, com a finalidade de permitir que a mente só pondere os significados julgados relevantes. É dentro de uma teia de significados intrinsecamente inter-relacionados que a firma deverá atuar para fortalecer a sua imagem, pois não tem a faculdade, no ambiente extremamente competitivo em que está inserida, de ignorá-la. Tendo em conta a relevância da imagem corporativa, é de fundamental importância que se saiba como mensurá-la. O presente estudo tem como objetivo precípuo desenvolver escala para medição de imagem corporativa de instituição privada de ensino superior. Para tanto, realizou-se pesquisa de survey com amostra de conveniência, a qual foi constituída por 230 respondentes. $O$ instrumento de coleta de dados foi o questionário estruturado e autoadministrado. Para tratamento dos dados, empregou-se a análise fatorial confirmatória, com auxílio da modelagem de equações estruturais. Os resultados

1 Doutor em Administração (COPPEAD/UFRJ). Mestrado em Administração e Desenvolvimento Empresarial (MADE/UNESA). Escola Superior Nacional de Seguros (ESNS/FUNENSEG). paulorcv2304@yahoo.com.br. (21) 97134-0118.

2 Mestre em Administração (MADE/UNESA). Mestrado em Administração e Desenvolvimento Empresarial (MADE/UNESA). angelodeangeli@yahoo.com.br. (21) 99251-4946

3 Doutor em Administração (PUC/RJ). Mestrado em Administração e Desenvolvimento Empresarial (MADE/UNESA). jasbfreitas@globo.com. (021) 99982-4642

4 Doutor em Engenharia de Produção (COPPE/UFRJ). Mestrado em Administração e Desenvolvimento Empresarial (MADE/UNESA). Escola Superior Nacional de Seguros (ESNS/ FUNENSEG). antonio.magalhaes@bcb.gov.br. (021) 99401-9560 
evidenciaram a solidez da escala proposta, acompanhados de inúmeros insights sugestivos de ações estratégicas.

Palavras-chave: Imagem Corporativa. Escala. Modelagem de Equações Estruturais.

\section{Abstract}

The corporate image serves as an interface between external reality and the individual, allowing him to abstract and simplify complex content on the organization, for the purpose of allowing the mind to ponder the meanings only deemed relevant. It is within a web of meanings intrinsically interrelated that the firm should act to strengthen their image because it has the power, in a highly competitive environment in which it operates, to ignore it. Given the importance of corporate image, it is essential to know how to measure it. This study aims to develop scale for measuring corporate image of a private institution of higher education. Therefore, research was carried out a survey with a convenience sample consisting of 230 respondents. The data collection instrument was a structured questionnaire and self-administered. For data processing we used confirmatory factor analysis, with the aid of structural equation modeling. The results show the soundness of the proposed scale, accompanied by numerous insights suggestive of strategic actions.

Keywords: Corporate image. Scale. Structural equation modeling.

\section{Introdução}

A imagem corporativa representa a interface entre a realidade exterior e o indivíduo, permitindo-lhe abstrair e simplificar conteúdos complexos sobre a organização, com a finalidade de permitir que a mente só pondere os significados julgados relevantes. A imagem corporativa é complexa e diversa. É dentro de uma teia de significados intrinsecamente inter-relacionados que a firma deverá atuar para fortalecer a sua imagem, pois não tem a faculdade, no ambiente extremamente competitivo em que está inserida, de ignorá-la. Nesse contexto, a imagem corporativa é um dos ativos mais nobres possuídos pela firma, constituindo o seu fortalecimento um objetivo que deve ser, continuamente, perseguido pela organização, independentemente do ramo em que atue. A imagem sólida constitui o instrumento mais eficaz para neutralizar ações competitivas, sendo imprescindível enquanto 
mecanismo de ampliação da participação da organização no mercado. Assim $_{2}$ torna-se imperioso que a empresa estabeleça um conjunto de ações estrategicamente encadeadas que Ihe possibilitem fortalecer a atitude positiva de seus públicos-alvos em relação a ela.

Com o acirramento da competição no mercado brasileiro privado de ensino superior, o que é atestado com o recente processo de fusão e incorporação de estabelecimentos privados de ensino superior, a questão acerca do fortalecimento da imagem corporativa dessas instituições torna-se impreterível, notadamente para faculdades isoladas. A sobrevivência, no curto prazo de faculdades isoladas e a ampliação de sua participação no mercado ao longo do tempo, depende, sobremaneira, da consolidação de sua imagem corporativa. Para fortalecer a imagem, é preciso que sejam conhecidas as variáveis que mais a influenciam, para que se possa desenhar um plano de ação eficaz que a torne mais resistente. Para tanto, é indispensável que se tenha uma escala de mensuração da imagem corporativa.

Dessa maneira, o presente trabalho objetiva avaliar escala desenvolvida para medir a imagem corporativa de instituição privada de ensino superior, tendo como subproduto informações acerca das variáveis mais relevantes para o seu fortalecimento, e está estruturado em quatro seções, além da presente introdução. Na segunda seção, serão discutidos os principais artigos que alicerçaram a pesquisa e o desenvolvimento do instrumento de coleta de dados. Na seção três, discutiremos a metodologia empregada no trabalho, apresentando informações acerca da ferramenta estatística que foi empregada no tratamento de dados. Na seção subsequente, discutiremos os resultados da pesquisa, ficando a última seção responsável pelas considerações finais.

\section{Imagem corporativa}

A literatura sobre imagem corporativa é caracterizada por apresentar contribuições de diferentes áreas acadêmicas, como o Marketing e a estratégia empresarial, entre outras. Por essa razão, há 
várias definições para o mesmo conceito, que dependem da perspectiva do pesquisador.

Para a finalidade desta investigação, julgamos mais apropriado a reunião dos principais estudos produzidos pela área de Marketing e de disciplinas correlatas em dois grandes grupos, discriminando a aplicação do conceito entre as organizações gerais e as instituições de ensino superior. Com esse objetivo em vista, a revisão de literatura discute, por um lado, a gênese e a evolução do conceito de imagem corporativa, dirigindo o foco, nesse caso, para negócios gerais e, de outro lado, são analisados os trabalhos direcionados especificamente às instituições de ensino.

\subsection{Gênese e evolução do conceito de imagem corporativa}

O trabalho pioneiro sobre imagem corporativa na área de Administração foi elaborado por Martineau (1958), que discute a essência do conceito. Segundo esse autor, a imagem corporativa é complexa e diversa, devendo ser moldada de forma clara e identificável. A imagem corporativa representa a impressão total que se tem de uma empresa, influenciando julgamentos, comportamentos e tomadas de decisão, cabendo observar que "a imagem corporativa de uma empresa aérea inclui mais significados do que aviões voando; simbolicamente projeta salas de espera, aeromoças, excelentes refeições e outros atributos" (MARTINEAU, 1958, p.191).

Martineau (1958) enfatiza que, quando as imagens são formadas na mente das pessoas, torna-se difícil a sua alteração, pois elas servem como filtros emocionais que são usados pelo indivíduo. A imagem sólida produz uma auréola, uma película protetora, refletindo sinais positivos. Ele finaliza as suas ponderações, afirmando que moldar ou ajustar a imagem corporativa é um trabalho altamente positivo e construtivo que deve ser encarado com vigor e entusiasmo, embora possam existir problemas de gerenciamento. Conclui ainda o autor que não existe uma imagem corporativa única, pois as firmas têm distintos públicos que constroem diferentes imagens corporativas. 
Kennedy (1977), por sua vez, ressalta o equívoco de se compensar o declínio dos mercados e o acirramento da competição com políticas de corte de gastos. Para neutralizar os competidores, seria preciso robustecer a imagem corporativa, o que poderia ser conseguido com o mínimo de despesas, simplesmente, porque os empregados são os principais vendedores da organização. Assim, para que fosse construída uma imagem nítida, consistente e favorável, caberia à administração superior comunicar, de forma clara e transparente, a política da empresa a todos os seus empregados.

O fato de considerar o empregado da empresa o principal responsável na construção da imagem corporativa, atuando na qualidade de seu vendedor para o público externo, rompe com a visão tradicional que concebia a campanha de propaganda como instrumento adequado para convencer o público de que a empresa era honesta, amiga dos clientes e que lhe ofertava o melhor produto ou prestava o melhor serviço. Kennedy (1977) realizou estudo empírico que comprovou a influência que os empregados exercem na forma como os públicos externos percebem a corporação, demonstrando, assim, o estreito vínculo entre a identidade e a imagem.

Dowling (1993) argumenta que cada pessoa possui sua própria percepção da empresa, o que implica dizer que a empresa possui muitas imagens e que a imagem resultante global seria a impressão real que existe na mente das pessoas a respeito da firma. As imagens são influenciadas pelo que as pessoas falam a respeito da empresa e do que ela divulga sobre ela mesma.

Para Grönroos (1993), a imagem representa o filtro que influencia a avaliação acerca do serviço experimentado. Uma imagem favorável realça a experiência; uma imagem desfavorável compromete a experiência. No longo prazo, a comunicação com o mercado realça e, de certa forma, modela a imagem.

De acordo com Fombrun (1996), a construção de forte imagem corporativa cria riqueza para empresa, gerando distintas vantagens competitivas que lhe permite atrair novos consumidores e investidores, assim como praticar preços mais elevados. Maior lealdade e produtividade 
dos empregados é outro resultado importante da imagem corporativa sólida. Paralelamente, a imagem forte também atrai novos fornecedores e possibilita negociações mais favoráveis, implicando menores preços para os insumos do processo produtivo. Finalmente, as receitas de vendas das empresas com imagem forte são mais estáveis e seus riscos de crise são menores.

A imagem corporativa sinaliza a qualidade dos produtos da companhia e, como tal, fornece informações sobre suas futuras performances. Por essa razão, a imagem é um valioso "input" para as decisões tomadas pelos consumidores nas compras de produtos ou serviços, principalmente para aqueles que estão relutantes ou indecisos em investir ou comprar (VENDELO, 1998; SHAPIRO, 1983).

Segundo Kotler (2000 p. 572), "a imagem é o conjunto de crenças, ideias e impressões que uma pessoa tem em relação a um objeto". Independentemente da consistência existente na imagem construída pelo público para determinada firma, a imagem influencia as decisões de consumo.

De acordo com Fombrun e Pan (2006), a imagem corporativa é fundamental para que as empresas produzam vantagens competitivas. Ela representa um ativo intangível que deve ser objeto de investimento continuado, pois funciona como escudo protetor em períodos críticos.

A imagem corporativa, conforme observou Martineau (1958), é complexa e diversa. Segundo Vieira e Freitas (2007), é dentro de uma teia de significados intrinsecamente inter-relacionados que a firma necessita atuar para fortalecer sua imagem, pois não tem a faculdade, no ambiente extremamente competitivo em que está inserida, de ignorá-la. A corporação não deveria apenas se preocupar com o consumidor, mas também com muitos outros públicos significativos, tais como investidores e sindicatos que precisam ser influenciados de formas distintas.

Herstein, Mitki e Jaffe (2008) destacaram que a administração da imagem corporativa tornou-se uma estratégia essencial para muitas organizações que visam lucro, mas que a sua adoção por organizações sem fins lucrativos ainda está sendo objeto de reflexão. O propósito 
do estudo foi verificar a estratégia de comunicação de Marketing de empresa israelense equivalente à Cruz Vermelha, para reforçar sua imagem corporativa numa era de terrorismo.

Gaines-Ross (2010) ressalta que a imagem de uma empresa representa os valores que os clientes atuais ou clientes potenciais têm em relação à organização. A imagem pode variar, dependendo de qual grupo está sendo considerado, uma vez que existe em vários níveis. Uma grande organização em rede, tal como uma rede de restaurantes, tem uma imagem geral, ao passo que uma organização local, como um restaurante isolado, numa pequena cidade, tem uma imagem empresarial local.

As novas mídias e redes sociais constituem, na visão desse autor, um poderoso arsenal que pode ser utilizado pelas pequenas empresas contra a imagem corporativa de concorrentes poderosos. É preciso, dessa maneira, que as corporações treinem equipes que, se for preciso, possam neutralizar, rapidamente, ataques que objetivem destruir ou enfraquecer a sua imagem corporativa.

Na opinião de Morgan e Minor (2011), para muitas empresas, o seu ativo mais precioso não está no balanço patrimonial, nem no capital humano, mas na sua imagem corporativa. Entretanto, na opinião deles, a imagem frágil pode sofrer sério comprometimento, se não forem tomados os devidos cuidados, tal como o ocorrido com a British Petroleum, quando houve vazamento de petróleo no Golfo do México. Embora durante muitos anos ela tenha investido na logomarca do "raio de sol aparecendo" e realizado diversas campanhas com a bandeira de que só "faz coisas boas", a imagem foi rapidamente depreciada, provocando a abrupta redução do valor da empresa no mercado. O risco associado ao comprometimento da imagem corporativa de uma empresa é um dos principais desafios que ela enfrenta.

\subsection{Imagem de instituição educacional}

Segundo Theus (1993), a imagem corporativa é um ativo essencial da universidade, cujo fortalecimento depende da qualidade de divulgação 
que ela faz de sua missão e do trabalho que realiza na comunidade a que serve.

Para Kotler e Armstrong (2004), mesmo organizações sem fins lucrativos podem praticar Marketing, quer seja para levantar fundos, atrair membros ou patrocinadores, quer seja simplesmente para facilitar seus contatos com os membros atuais ou potenciais.

Segundo Vendelo (1998), a imagem sólida é muito importante para a organização, pois isto a torna capaz de obter melhores preços para seus produtos, ganhar contratos favoráveis com bancos, atrair alunos, se for universidade, conquistar mais facilmente consumidores etc., pois a imagem corporativa constitui um valioso ativo para as organizações. Ao contrário, uma empresa com reputação ruim encontrará situações onde poucas oportunidades lhe serão abertas e os constrangimentos serão muitos.

Levando-se em conta que fatores externos influenciam a construção da imagem corporativa, Kazoleas, Kim e Moffitt (2001) afirmam que a imagem não é controlada pela organização, como postulam alguns autores. Esta afirmação foi calcada em resultados de investigação acerca da imagem corporativa de universidade pública norte-americana, sob a perspectiva do público externo, com tratamento quantitativo de dados e coleta de dados via telefone, com base em questionário estruturado. Os resultados da pesquisa confirmam a existência de múltiplas imagens da universidade analisada. A descoberta da existência de múltiplos fatores constituintes da imagem - pessoal, ambiental e organizacional - também foram insights relevados pelo estudo.

Por último, os autores supracitados observam que a imagem é o resultado de uma disputa complexa e multifacetada dos atributos processados pelos indivíduos, com base nas mensagens enviadas pelas empresas, bem como das informações sociais, históricas e de experiências pessoais que Ihes são comunicadas, seja de forma intencional ou não.

Vieira, Trocolli e Silva (2011) concluíram que, no tocante à percepção de qualidade do serviço prestado por instituição privada de 
ensino superior, não apenas o elemento humano é o mais importante, notadamente o corpo docente, mas também exerce impacto positivo sobre a percepção quanto aos ativos tangíveis.

\section{Metodologia}

A presente seção apresenta os procedimentos metodológicos que foram observados no estudo, cuja finalidade precípua era investigar a validade de escala hipotética para mensuração de imagem corporativa de instituição privada de ensino superior, extraindo insights daí decorrentes.

A pesquisa realizada teve uma abordagem quantitativa, que é, segundo Cidade, Carvalho e Vieira (2010), a mais apropriada para o estudo em questão, pois avalia as relações entre os construtos. 0 procedimento utilizado na obtenção de dados foi a pesquisa na forma de levantamento (survey) que é, conforme a definição de Hair et al. (2009), o procedimento em que se emprega um questionário estruturado para colher muitas informações de parcela da população. A coleta de dados seguiu o procedimento de corte transversal, tendo sido realizada entre setembro e outubro de 2011.

\subsection{População e amostra}

A população da pesquisa é o conjunto de estudantes das instituições privadas de ensino superior do Rio de Janeiro. A amostra foi constituída por 230 alunos dos cursos de Administração, Ciências Contábeis e Marketing de instituição privada de ensino superior, com sede no Rio de Janeiro, matriculados do $2^{\circ}$ ao $5^{\circ}$ períodos.

Segundo Fink (1995), quanto mais representativa a população, melhor é a amostra. Nenhuma amostra é perfeita, podendo variar o grau de erro ou viés. A observação de algumas diretrizes quando a amostra é selecionada, como considerar o objetivo da pesquisa, aumenta a chance de se extrair uma amostra mais adequada à pesquisa que se pretende conduzir. Deve-se também estabelecer as diretrizes definidoras da participação dos indivíduos na amostra. 
O presente estudo emprega amostra não probabilística, por conveniência, constituída, conforme informamos anteriormente, por 230 respondentes.

Em Modelagem de Equações Estruturais (MEE), o tamanho adequado para a amostra é cerca de 200 observações, quando se emprega estimação por máxima verossimilhança, sendo que Hair et al. (2009) e Vieira e Ribas (2011) afirmam que quanto maior a complexidade do modelo, mais observações são necessárias. Há autores que consideram o tamanho mínimo da amostra constituído de 100 observações; outros autores postulam um mínimo de 150 observações. As chances de obtenção de valores ou resultados alinhados com a realidade aumentam consideravelmente com 100 observações e são ainda bem melhores com 300 (SILVA, 2006). Pelas razões expostas anteriormente, pode-se afirmar que o tamanho da amostra (230 observações) é apropriado para a pesquisa realizada.

\subsection{Instrumento de coleta de dados}

Acoleta de dados foi realizada por meio de questionário estruturado e autoadministrado, com cinco opções de respostas do tipo Likert.

Existe uma estreita associação entre os itens do questionário e as variáveis observadas do modelo. Por essa razão, o instrumento de coleta de dados necessita ter alicerces profundos na literatura acadêmica sobre o problema que será investigado (VIEIRA; RIBAS, 2011).

Em MEE trabalha-se, usualmente, com variáveis latentes e variáveis observadas. As variáveis que não são diretamente mensuráveis, que são supostamente as causas que provocam a variação de um conjunto de variáveis observadas são, frequentemente, denominadas variáveis latentes ou fatores. As variáveis observadas são efetivamente medidas com base nas respostas dos respondentes, as quais foram selecionadas entre as opções de resposta para cada item do questionário estruturado. 


\subsection{Variáveis latentes}

As variáveis latentes relacionadas à pesquisa sobre a escala para mensuração da imagem corporativa de instituição privada de ensino superior foram as seguintes:

1) ConfUni: variável latente relacionada à confiança na Universidade;

2) Qualen: variável latente que mensura a qualidade do ensino na Universidade;

3) Qualinst: variável que atesta a qualidade das instalações na Universidade;

4) Qualaten: variável latente que analisa a qualidade no atendimento ao aluno.

\subsection{Variáveis observadas}

As variáveis observadas da pesquisa acerca da construção de escala para mensuração da imagem corporativa de instituição privada de ensino superior, as respectivas variáveis latentes (construtos), os itens do questionário e as principais referências bibliográficas que fundamentaram a elaboração do questionário foram listadas no Quadro 1: 


\section{Quadro 1 - Variáveis latentes (construtos), variáveis observadas, itens do questionário e referências bibliográficas.}

\begin{tabular}{|c|c|c|c|c|}
\hline $\mathbf{N}^{\circ}$. & Item & Variável latente & $\begin{array}{l}\text { Variável } \\
\text { observada }\end{array}$ & Referencial \\
\hline 1 & $\begin{array}{l}\text { Esta Universidade se destaca na atração de } \\
\text { novos alunos }\end{array}$ & \multirow{6}{*}{$\begin{array}{l}\text { ConfUni } \\
\text { Confiança na } \\
\text { Universidade }\end{array}$} & Confia1 & \multirow{6}{*}{$\begin{array}{l}\text { CARVALHO (2009a); } \\
\text { VENDELO (1998); } \\
\text { THOMAZ (2010); } \\
\text { GRONROOS (2009); } \\
\text { CIDADE (2010); } \\
\text { ANDREASSEN (1998); } \\
\text { VIEIRA (2004); SILVA } \\
(2009) .\end{array}$} \\
\hline 2 & $\begin{array}{l}\text { Esta Universidade produz sólida formação } \\
\text { profissional em seus alunos }\end{array}$ & & Confia2 & \\
\hline 3 & $\begin{array}{l}\text { Empresas conceituadas preferem contratar } \\
\text { profissionais formados nesta Universidade }\end{array}$ & & Confia3 & \\
\hline 4 & $\begin{array}{l}\text { Esta Universidade procura se ajustar às } \\
\text { mudanças que ocorrem no mercado de trabalho }\end{array}$ & & Confia4 & \\
\hline 5 & $\begin{array}{l}\text { Esta Universidade contribui positivamente para o } \\
\text { bem-estar da sociedade }\end{array}$ & & Confia5 & \\
\hline 6 & $\begin{array}{l}\text { Esta Universidade mantém uma comunicação } \\
\text { eficiente com os alunos }\end{array}$ & & Confia6 & \\
\hline 7 & $\begin{array}{l}\text { O aluno acredita na excelência de qualidade do } \\
\text { Curso superior desta Universidade }\end{array}$ & \multirow{11}{*}{$\begin{array}{l}\text { Qualen } \\
\text { Qualidade de } \\
\text { ensino }\end{array}$} & Quali1 & \multirow{11}{*}{$\begin{array}{l}\text { CARVALHO (2009a); } \\
\text { VENDELO (1998); } \\
\text { KAZOLEAS (2001); } \\
\text { GRONROOS(2009); } \\
\text { CIDADE (2010); } \\
\text { ANDREASSEN (1998); } \\
\text { VIEIRA (2004); SILVA } \\
(2009)\end{array}$} \\
\hline 8 & $\begin{array}{l}\text { As disciplinas do meu Curso são fundamentais } \\
\text { para formação profissional dos alunos }\end{array}$ & & Quali2 & \\
\hline 9 & $\begin{array}{l}\text { Os professores dominam o conteúdo da } \\
\text { disciplina que lecionam }\end{array}$ & & Quali3 & \\
\hline 10 & $\begin{array}{l}\text { O conteúdo das disciplinas do meu Curso } \\
\text { determina uma sólida formação profissional }\end{array}$ & & Quali4 & \\
\hline 11 & $\begin{array}{l}\text { Sou reprimido quando expresso minhas opiniões } \\
\text { aos professores }\end{array}$ & & Quali5 & \\
\hline 12 & $\begin{array}{l}\text { Os professores são pontuais em seus } \\
\text { compromissos acadêmicos }\end{array}$ & & Quali6 & \\
\hline 13 & $\begin{array}{l}\text { A grade curricular de meu curso revela } \\
\text { preocupações com a sólida formação profissional }\end{array}$ & & Quali7 & \\
\hline 14 & $\begin{array}{l}\text { Os professores tem capacidade didática para } \\
\text { ensinar }\end{array}$ & & Quali8 & \\
\hline 15 & $\begin{array}{l}\text { As formas de avaliação do aprendizado do Curso } \\
\text { são adequadas }\end{array}$ & & Quali9 & \\
\hline 16 & $\begin{array}{l}\text { Os professores demonstram interesse em auxiliar } \\
\text { os alunos na solução de eventuais problemas }\end{array}$ & & Quali10 & \\
\hline 17 & $\begin{array}{l}\text { Os professores esclarecem as dúvidas surgidas } \\
\text { em aula }\end{array}$ & & Quali11 & \\
\hline 18 & $\begin{array}{l}\text { As instalações físicas das salas de aula são } \\
\text { apropriadas }\end{array}$ & \multirow{3}{*}{$\begin{array}{l}\text { Qualinst } \\
\text { Qualidade das } \\
\text { instalações }\end{array}$} & Qualins1 & \multirow{3}{*}{$\begin{array}{l}\text { VENDELO (1998); } \\
\text { KAZOLEAS (2001); } \\
\text { VIEIRA (2004); SILVA } \\
\text { (2009). }\end{array}$} \\
\hline 19 & $\begin{array}{l}\text { Os equipamentos utilizados em meu curso estão } \\
\text { em boas condições de uso }\end{array}$ & & Qualins2 & \\
\hline 20 & A limpeza da sala de aula é feita adequadamente & & Qualins3 & \\
\hline
\end{tabular}


Paulo Roberto da Costa Vieira, Angelo Roberto Calderaro de Angeli, Jorge Augusto de Sá Brito e Freitas e Antônio Carlos Magalhães da Silva

\begin{tabular}{|c|c|c|c|c|}
\hline 21 & $\begin{array}{l}\text { A Secretaria desta Universidade soluciona } \\
\text { as demandas dos alunos }\end{array}$ & \multirow{5}{*}{$\begin{array}{l}\text { Qualaten } \\
\text { Qualidade no } \\
\text { atendimento }\end{array}$} & QualiAt1 & \multirow{5}{*}{$\begin{array}{l}\text { VENDELO (1998); } \\
\text { VIEIRA (2004); SILVA } \\
\text { (2009). }\end{array}$} \\
\hline 22 & $\begin{array}{l}\text { A Coordenação de meu Curso resolve } \\
\text { os problemas de ensino do Curso que } \\
\text { frequento }\end{array}$ & & QualiAt2 & \\
\hline 23 & $\begin{array}{l}\text { Os professores estão acessíveis às } \\
\text { solicitações dos alunos fora do horário de } \\
\text { aula }\end{array}$ & & QualiAt3 & \\
\hline 24 & $\begin{array}{l}\text { A qualidade de atendimento desta } \\
\text { Universidade corresponde às expectativas } \\
\text { dos alunos }\end{array}$ & & QualiAt4 & \\
\hline 25 & $\begin{array}{l}\text { A Secretaria desta Universidade conhece } \\
\text { os serviços que executa }\end{array}$ & & QualiAt5 & \\
\hline
\end{tabular}

Fonte: Elaboração própria.

\subsection{Hipóteses do modelo estrutural}

As hipóteses do modelo estrutural estão descritas a seguir:

ConfUni apresenta covariância com Qualen.

Qualen apresenta covariância com Qualinst.

Qualinst apresenta covariância com Qualaten.

Qualaten apresenta covariância com ConfUni.

A validade da escala proposta é verificada com a significância das estimativas dos parâmetros e os índices de ajustamento obtidos com a realização da análise fatorial confirmatória.

\subsection{Modelagem de equações estruturais}

A análise fatorial exploratória agrupa variáveis observadas (indicadores) que descrevem determinada dimensão, a qual é comumente denominada fator (variável latente ou construto). Mais especificamente, o caráter de determinado construto latente fica definido pelas variáveis observadas que apresentam maiores cargas sobre o fator. $\mathrm{O}$ caráter exploratório da ferramenta fica manifesto quando se considera que, dada uma constelação de variáveis observadas, não se sabe, a priori, aquelas que serão agrupadas para definição de determinada dimensão subjacente (HAIR et al, 2009). 
A MEE possibilita alterar a natureza da análise fatorial de exploratória para confirmatória, já que é, nesse último caso, o pesquisador quem especifica, fundamentado em postulados teóricos, quais são as variáveis observadas que estão associadas a determinado fator. A MEE também possibilita que seja realizado teste estatístico de significância para as estimativas dos parâmetros e sejam produzidos índices acerca da qualidade do ajustamento (HAIR et al., 2009).

A análise fatorial confirmatória realizada no presente estudo foi baseada em estruturas de covariância, cujo procedimento pressupõe a existência de indicadores reflexivos, o que significa admitir que o construto exerce influência sobre as variáveis observadas, possibilitando a inclusão de erro de mensuração. A estimação utilizada foi de máxima verossimilhança, uma vez que as variáveis observadas apresentaram normalidade adequada (VIEIRA ; RIBAS, 2011).

Vieira e Ribas (2011) definem MEE como um conjunto de técnicas estatísticas que inclui a análise de caminho e fatorial, integrando-as em modelos completos de regressão estrutural, estimando simultaneamente os parâmetros de uma série de equações de regressão linear interdependentes, embora separadas.

Segundo esses autores, em MEE, o primeiro passo é a especificação do modelo que deve possuir profundas raízes teóricas. A especificação inicial pode tomar a forma de um diagrama ou uma sequência de equações. A MEE é um procedimento de natureza essencialmente confirmatória, com o objetivo de avaliar modelos por intermédio de testes de qualidade do ajustamento que verificam se a estrutura de variância e covariância da matriz de dados é consistente com a estrutura do modelo do pesquisador.

A mensuração das variáveis latentes no presente trabalho, Confiança na Universidade, Qualidade de Ensino, Qualidade das Instalações e no Atendimento - é realizada de forma indireta, por intermédio das 25 variáveis observadas, representativas de suas múltiplas características essenciais. Com base nas variáveis observadas, a MEE não apenas estima os construtos, como também, testa a qualidade 
de ajustamento global do modelo, bem como a consistência de seus parâmetros.

De acordo com Vieira e Ribas (2011), após a especificação do modelo, é preciso obter as estimativas dos parâmetros, ou seja, as estimativas dos coeficientes que representam efeitos diretos, variâncias e covariâncias de variáveis latentes. O programa estatístico considerado no presente estudo é o AMOS 4.0 (Analysis of Moment Structures), o qual determina as estimativas que reproduzem a matriz observada de variância e covariância, com a maior aproximação possível. A estimação de máxima verossimilhança é a mais empregada. São calculadas estimativas baseadas na maximização de probabilidades (verossimilhança) de que as covariâncias observadas são extraídas de uma população que supostamente é a mesma que a refletida nas estimativas dos coeficientes (ARBUCKLE ; WOTHKE, 1999).

A segunda parte, referente à avaliação do modelo, diz respeito ao grau de excelência de seu ajustamento global. A MEE trabalha com diferentes medidas ou índices de ajustamento global.

De acordo com Vieira e Ribas (2011), a MEE não utiliza, no processo de estimação, os dados diretamente coletados, mas sim a matriz de covariância produzida a partir dos referidos dados. De fato, com base no modelo construído de equações estruturais, é gerada uma matriz de covariância $(\Sigma)$ denominada matriz de covariância reproduzida, com $\{[p(p+1)] / 2\}$ elementos não redundantes, sendo $p o$ número de variáveis observadas. Os elementos de $\Sigma$ são todos funções dos parâmetros do modelo. Cada elemento da matriz $\Sigma$ tem um elemento numérico correspondente na matriz de covariância observada (S) obtida a partir dos valores da amostra para as variáveis $V_{i}(i=1, \ldots, p)$.

O teste clássico de excelência de ajustamento - o teste quiquadrado $\left(\mathrm{X}^{2}\right)$ - avalia a magnitude de discrepância entre $\mathrm{S}$ e $\Sigma$. Ou seja, o modelo se ajusta aos dados observados na mesma extensão da equivalência existente entre a matriz de covariância gerada pelo modelo $(\Sigma)$ e a matriz de covariância observada (S). Em ajustamento de excelência, a matriz de resíduos tende a zero. Ao contrário da lógica usual de inferência estatística, $H_{0}$ estabelece, em MEE, que o 
modelo que se deseja apoiar é "verdadeiro", enquanto $\mathrm{H}_{1}$ considera que o modelo não é "verdadeiro". Segue-se, portanto que, em MEE, o pesquisador não deseja rejeitar $\mathrm{H}_{\mathrm{o}}$. A consistência global do modelo é avaliada primariamente por meio do teste $X^{2}$. Uma estatística $X^{2}$ de magnitude pouco expressiva $(p>0,05)$ indica que o modelo se ajusta adequadamente, evidenciando que o modelo pode reproduzir a matriz de covariância da população.

O teste $X^{2}$ é o único teste de significância estatística da MEE, muito embora sejam calculados diversos índices de excelência de ajustamento. Há uma diversidade de índices que assumem valores no intervalo de 0 a 1 , indicando melhora no ajustamento do modelo à medida que o índice se aproxima de 1. Convém notar que os índices de ajustamento representam distintas formas de expressar a distância entre a matriz de covariância da amostra S e a matriz de covariância gerada pelo modelo $\Sigma$.

Segundo Vieira e Ribas (2011), há, fundamentalmente, quatro classes de índices de excelência de ajustamento: índices absolutos; índices comparativos (relativos ou incrementais); índices baseados em parcimônia; e índices diversos.

O primeiro índice absoluto é o índice de ajustamento comparativo (CFI - Comparative Fit Index), que também é conhecido como índice de ajustamento comparativo de Bentler, o qual contrasta o ajustamento do modelo hipotético com o modelo nulo (independente). $\mathrm{O}$ índice de ajustamento normalizado (NFI - Normed Fit Index), também conhecido como índice de ajustamento normalizado Bentler-Bonett, foi desenvolvido como alternativa ao $\mathrm{CFI}$, penalizando o tamanho da amostra. $\mathrm{O}$ índice de Tucker-Lewis (TLI) é similar ao NFI, embora penalize a complexidade do modelo. O TLI é relativamente independente do tamanho da amostra. $\mathrm{O}$ TLI próximo de um indica um bom ajustamento. Quando o TLI é inferior a 0,90, o modelo deve ser revisto, de acordo com Vieira e Ribas (2011).

Os índices de ajustamento baseados em parcimônia são, usualmente, muito menores do que outras medidas de ajustamento. Valores superiores a 0,60 são, geralmente, considerados satisfatórios. 
No grupo de índices diversos, destaca-se, na qualidade de representante de excelência, a raiz do erro quadrático médio de aproximação (RMSEA - Root Mean Square Error of Approximation), a qual constitui um critério muito informativo da modelagem da estrutura de covariância, pois o CFI e a RMSEA estão entre as medidas menos afetadas pelo tamanho da amostra.

\section{Resultados}

Para avaliar a qualidade do instrumento de coleta de dados, verificando sua confiabilidade, foi calculado o Alfa de Cronbach. Para a variável latente Confiança na Universidade (ConfUni), o coeficiente de Cronbach foi de 0,699. Já para a variável latente Qualidade de Ensino, o Alfa foi de 0,799 , com 11 itens analisados. A variável latente Qualidade das Instalações (Qualinst) obteve um Alfa de 0,668. Todavia, considerando que, nesse construto, há apenas três itens, a sua confiabilidade interna não deve ser objeto de preocupação. Finalmente, para a variável latente Qualidade no Atendimento (Qualaten), o coeficiente de Cronbach foi de 0,793 .

A análise das informações deve ter o seu foco centrado em três aspectos: 1) avaliação do sinal e da magnitude das estimativas dos parâmetros à luz da teoria subjacente à construção do modelo, 2) verificação da existência de erros padrão inadmissíveis e, 3) avaliação da razão crítica (C.R.), cujo cálculo é feito promovendo a divisão da estimativa do parâmetro pelo erro padrão (VIEIRA e RIBAS, 2011).

A informação inicial do AMOS 4.0 resume, conforme mostra a Tabela 1, os parâmetros do modelo, indicando o tamanho da amostra, o número de parâmetros que devem ser estimados e os graus de liberdade. A amostra tem 230 observações, existindo 271 graus de liberdade. $O$ processo de estimação gerou uma solução admissível, cujo panorama geral é estimado com o valor $\chi^{\underline{2}}(727,584)$, juntamente com os graus de liberdade (271) e o nível de probabilidade $(0,000)$. 
Tabela 1 - Resumo dos parâmetros para o modelo hipotético

\begin{tabular}{c|c}
\hline Tamanho da amostra & 230 \\
\hline Cálculo dos graus de liberdade & 350 \\
\hline Número de momentos amostrais distintos & 79 \\
\hline Número de distintos parâmetros a serem estimados & 271 \\
\hline Graus de liberdade & 727,584 \\
\hline Qui-quadrados & 0,000 \\
\hline Nível de probabilidade
\end{tabular}

Fonte: Elaboração própria

A Tabela 2 cientifica o método de estimação, as estimativas dos pesos de regressão, os erros padrão (E.P) e as respectivas razões críticas (R.C). Ou seja, são exibidas informações acerca do ajustamento dos parâmetros individuais. As estimativas dos parâmetros do modelo de mensuração devem ser avaliadas em termos teóricos e estatísticos. Sob a perspectiva teórica, os sinais e magnitudes dos coeficientes devem estar em conformidade com os requisitos teóricos. Sob o ângulo estatístico, as estimativas dos parâmetros não podem estar associadas a resultados impróprios, tais como variâncias negativas ou correlações superiores à magnitude 1 (VIEIRA e RIBAS, 2011).

Tabela 2 - Estimativas dos parâmetros do modelo hipotético.

\begin{tabular}{|c|c|c|c|}
\hline Pesos de Regressão & Estimativa & Erro Padrão & R.C. \\
\hline Quali1 $\leftarrow$ Qualen & 1,000 & & \\
\hline Quali2 $\leftarrow$ Qualen & 0,909 & 0,127 & 7,157 \\
\hline Quali3 $\leftarrow$ Qualen & 0,794 & 0,132 & 6,016 \\
\hline Quali4 $\leftarrow$ Qualen & 1,108 & 0,141 & 7,849 \\
\hline Quali5 $\leftarrow$ Qualen & 0,575 & 0,148 & 3,895 \\
\hline Quali6 $\leftarrow$ Qualen & 0,706 & 0,128 & 5,529 \\
\hline Quali7 $\leftarrow$ Qualen & 0,682 & 0,145 & 4,694 \\
\hline Quali8 $\leftarrow$ Qualen & 0,855 & 0,132 & 6.458 \\
\hline Quali9 $\leftarrow$ Qualen & 0,750 & 0,123 & 6,119 \\
\hline Quali10 $\leftarrow$ Qualen & 0,817 & 0,131 & 6,238 \\
\hline Quali11 $\leftarrow$ Qualen & 0,697 & 0,104 & 6,716 \\
\hline Confia1 $\leftarrow$ ConfUni & 1,000 & & \\
\hline Confia2 $\leftarrow$ ConfUni & 1,161 & 0,185 & 6,278 \\
\hline Confia3 $\leftarrow$ ConfUni & 0,988 & 0,169 & 5,844 \\
\hline Confia4 $\leftarrow$ ConfUni & 1,043 & 0,176 & 5,911 \\
\hline Confia5 $\leftarrow$ ConfUni & 0,747 & 0,141 & 5,280 \\
\hline
\end{tabular}




\begin{tabular}{|c|c|c|c|}
\hline Confia6 $\leftarrow$ ConfUni & 1,179 & 0,233 & 5,051 \\
\hline QualiAt5 $\leftarrow$ Qualaten & 1,000 & & \\
\hline QualiAt4 $\leftarrow$ Qualaten & 0,943 & 0,102 & 9,241 \\
\hline QualiAt3 $\leftarrow$ Qualaten & 0,439 & 0,094 & 4,687 \\
\hline QualliAt2 $\leftarrow$ Qualaten & 1,130 & 0,113 & 10,014 \\
\hline QualiAt1 $\leftarrow$ Qualaten & 1,280 & 0,117 & 10,983 \\
\hline Qualins3 $\leftarrow$ Qualinst & 1,000 & & \\
\hline Qualins2 $\leftarrow$ Qualinst & 2,234 & 0,389 & 5,743 \\
\hline Qualins1 $\leftarrow$ Qualinst & 1,414 & 0,242 & 5,835 \\
\hline
\end{tabular}

Fonte: Elaboração própria.

Arazão crítica (R.C) permite testar se a estimativa é estatisticamente diferente de zero. Considerando um nível de significância de 5\%, a razão crítica necessita ser superior a $\pm 1,96$, para que seja rejeitada a hipótese de que a estimativa é zero. A R.C verifica se o parâmetro é importante para o modelo. Os resultados do programa AMOS 4.0 são apresentados separadamente para os pesos de regressão e as variâncias. No caso do nosso modelo hipotético, todas as estimativas individuais são não apenas estatisticamente consistentes, mas também exibem robustez teórica (VIEIRA ; RIBAS, 2011).

De fato, as razões críticas (R.C) de todas as variáveis observadas dos construtos do modelo são mostradas na Tabela 2, onde podemos observar a existência de significância estatística (R.C > 1,96), para todas as variáveis observadas dos construtos do modelo, quais sejam: Confiança na Universidade (ConfUni), Qualidade de Ensino (Qualen), Qualidade das Instalações (Qualinst) e Qualidade no Atendimento (Qualaten).

No tocante ao construto Qualidade de Ensino (Qualen), a variável observada Quali4 referente ao item do questionário "O conteúdo das disciplinas do meu Curso determina uma sólida formação profissional" é o item mais importante do construto, exibindo, em consequência, o maior peso de regressão entre as variáveis observadas que estão vinculadas ao aludido construto, acompanhado de significância estatística. Ainda no construto Qualen, a variável observada Quali2, a qual representa "As disciplinas do meu Curso são fundamentais para a formação profissional 
dos alunos", exibe o segundo maior peso de regressão, acompanhado de significância estatística, também merecendo destaque.

Além de atestar a qualidade do corpo docente, dois itens do questionário revelaram a existência de impacto positivo exercido pelo docente: "Os professores dominam o conteúdo da disciplina que lecionam" (Quali3), com peso de regressão de 0,794, e "Os professores têm capacidade didática para ensinar" (Quali8), com peso de regressão de 0,855 .

Capacidade didática e excelência de conteúdo das disciplinas exercem, de fato, impacto positivo na avaliação da qualidade de ensino, conforme atestou Silva (2009) em seu estudo com universitários da Unifeso, da cidade fluminense de Teresópolis. Com efeito, a análise fatorial realizada pelo referido autor, revelou o componente humano, mais especificamente o corpo docente, como o fator mais importante na avaliação dos alunos quanto à qualidade do Curso do qual participavam.

No que diz respeito ao construto "Qualidade no Atendimento" (Qualaten), as variáveis observadas QualiAt1, "A Secretaria desta Universidade soluciona as demandas dos alunos", e QualiAt4, "A qualidade de atendimento desta Universidade corresponde às expectativas dos alunos", destacaram-se como as mais relevantes, uma vez que seus pesos de regressão foram os mais elevados entre aquelas variáveis observadas que sofreram influência de Qualaten.

A Tabela 3 está relacionada ao modelo estrutural. Com efeito, o modelo estrutural admite a existência de covariância entre os construtos. O modelo apresenta significância estatística (R.C.>1,96), para todas as covariâncias, exceto para a covariância entre Qualinst e ConfUni. Ou seja, não há significância para covariância entre a qualidade das instalações e a confiança na Universidade, uma vez que a R.C foi de $-0,052$. 
Tabela 3 - Informações sobre o modelo estrutural

\begin{tabular}{l|c|c|c}
\hline Covariância & Estimativa & E.P & R.C \\
\hline Qualen $\leftarrow--\rightarrow$ ConfUni & 0,183 & 0,036 & 5,060 \\
\hline Qualinst $\leftarrow---\rightarrow$ ConfUni & -0.001 & 0,012 & $-0,052$ \\
\hline Qualen $\leftarrow--\rightarrow$ Qualaten & 0,054 & 0,021 & 2,614 \\
\hline Qualinst $\leftarrow---\rightarrow$ Qualaten & 0,111 & 0,028 & 3,998 \\
\hline
\end{tabular}

Fonte: Elaboração própria.

Não obstante o Alpha de Cronbach seja empregado para avaliar a consistência interna do questionário, para avaliar o modelo de mensuração utiliza-se, além do exame dos sinais e significância das cargas de cada variável observada, a confiabilidade composta de cada construto, para informar o quanto as variáveis observadas são efetivamente indicativas do construto. Hair et al (2009) recomendam o patamar de 0,70 para que a confiabilidade do modelo de mensuração seja considerada aceitável.

A Tabela 4 informa a confiabilidade composta de cada construto, atestando confiabilidade adequada para o modelo de mensuração do estudo.

Tabela 4 - Confiabilidade composta do construto

\begin{tabular}{l|c}
\hline Construto & Confiabilidade Composta \\
\hline Qualen & 0,7934 \\
\hline ConfUni & 0,7092 \\
\hline Qualaten & 0,7962 \\
\hline Qualinst & 0,6787 \\
\hline
\end{tabular}

Fonte: Elaboração própria.

Na Tabela 5, informa-se o número de parâmetros (NPAR), a discrepância mínima (CMIN), os graus de liberdade (DF), a probabilidade (p) e a razão (CMIN/DF).

O valor CMIN de 727,584 representa a discrepância entre as matrizes de covariância S e $\Sigma$, constituindo, essencialmente, o teste razão de verossimilhança, o qual é geralmente expresso como a estatística $X^{2}$ (VIEIRA e RIBAS, 2011). Na medida em que a $X^{2}$ é extremamente sensível ao tamanho da amostra, emprega-se a razão $X^{2} /$ graus de liberdade em lugar de $x^{2}$. 
No AMOS 4.0, a razão X²/graus de liberdade aparece como CMIN/ DF (discrepância mínima/graus de liberdade), a qual mostra a diferença entre as matrizes de covariância observada e estimada. A estatística de ajustamento CMIN/graus de liberdade de 2,685 está situada no intervalo de aceitação do modelo, ou seja, aquém de três (ARBUCLE e WOTHKE, 1999).

Tabela 5 - Índices de qualidade de ajustamento para o modelo hipotético

\begin{tabular}{l|c|c|c|c|c}
\hline Resumo dos Modelos & NPAR & CMIN & DF & p & CMIN/DF \\
\hline Modelo Padrão & 79 & 727,584 & 271 & 0,00 & 2,685 \\
\hline Modelo Saturado & 350 & 0,00 & 0 & & \\
\hline Modelo Independente & 25 & $18.440,57$ & 325 & 0,00 & 56,740 \\
\hline
\end{tabular}

Fonte: Elaboração própria.

Muito embora o valor de 0,90 tenha sido considerado, durante longo tempo, o mínimo para os índices comparativos de qualidade de ajustamento (relativo ou incremental) representativos de modelos de bom ajustamento, Byrne (2001) menciona a revisão do aludido piso para 0,95. Na Tabela 6, independentemente do critério adotado, todos os índices de ajustamento comparativo do modelo hipotético (NFI, IFI, TLI e CFI) superaram o mínimo exigido. O NFI (normal fit index) faz a comparação entre o modelo hipotético e o modelo independente, sendo que um NFI > 0,95 indica um bom ajustamento do modelo, segundo Lemke (2005). Como o NFI do modelo hipotético exibiu um NFI de 0,961, há, dessa maneira, evidência suficiente de que o modelo apresenta bom ajustamento. $\mathrm{O}$ índice de ajustamento incremental (IFI) é relativamente independente do tamanho da amostra e também deve ser superior a 0,95 , segundo os critérios mais rígidos, para que o modelo exiba bom ajustamento.

O índice de ajustamento comparativo (CFI) ou índice de ajustamento comparativo de Bentler contrasta o ajustamento do modelo hipotético com o modelo nulo (independente). A magnitude no estudo foi de 0,975 . 
O TLI (índice de Tucker-Lewis) é relativamente independente do tamanho da amostra e próximo de 1 indica bom ajustamento. No nosso modelo, o índice TLI foi de 0,97 exibindo ajustamento adequado.

Tabela 6 - Índices absolutos de qualidade de ajustamento para o modelo hipotético

\begin{tabular}{l|c|c|c|c}
\hline Resumo dos Modelos & NFI & IFI & TLI & CFI \\
\hline Modelo Padrão & 0,961 & 0,975 & 0,970 & 0,975 \\
\hline Modelo Saturado & 1,000 & 1,000 & 1,000 & \\
\hline Modelo Independente & 0,000 & 0,000 & 0,000 & 0,000 \\
\hline
\end{tabular}

Fonte: Elaboração própria.

Na Tabela 7, os índices de parcimônia de ajustamento de 0,834 (PRATIO), 0,801 (PNFI) e 0,813 (PCFI) são satisfatórios, com valores acima de 0,60. A razão de parcimônia (PRATIO) é a razão dos graus de liberdade do modelo do pesquisador em relação aos graus de liberdade do modelo nulo; ele não é um teste de excelência de ajustamento em si, mas é empregado em medidas de qualidade do ajustamento. Desse modo, o índice de ajustamento normalizado de parcimônia (PNFI) e o índice de ajustamento comparativo de parcimônia (PCFI) que recompensam modelos parcimoniosos são resultantes da multiplicação do PRATIO sobre o NFI e o CFI, respectivamente.

Tabela 7 - Índices de parcimônia de ajustamento

\begin{tabular}{l|c|c|c}
\hline Resumo & PRATIO & PNFI & PCFI \\
\hline Modelo Padrão & 0,834 & 0,801 & 0,813 \\
\hline
\end{tabular}

Fonte: Elaboração própria.

A Tabela 8 mostra a raiz do erro quadrático médio de aproximação, a RMSEA (Root Mean Square Error of Approximation). Em modelagem de equações estruturais, esse índice de qualidade de ajustamento é considerado um dos mais importantes, já que é um dos menos afetados pelo tamanho da amostra. Byrne (2001) destaca que esse índice é considerado o critério mais informativo da modelagem de estrutura de covariância. 
Tabela 8 - Índice diverso de qualidade do ajustamento para o modelo hipotético

\begin{tabular}{l|l|l|l|l}
\hline Resumo dos Modelos & RMSEA & LO 90 & HI 90 & PCLOSE \\
\hline Modelo Padrão & 0,086 & 0,078 & 0,093 & 0,000 \\
\hline Modelo Independente & 0,493 & 0,487 & 0,499 & 0,000 \\
\hline
\end{tabular}

Fonte: Elaboração própria.

O valor da RMSEA gerado pelo modelo da pesquisa $(0,086)$ é indicativo de ajustamento pobre. De fato, valores que variam entre 0,08 e 0,10 indicam ajustamento pobre, de acordo com Arbuckle e Wothke (1999). Cabe atentar que, além da estimativa pontual da RMSEA, o programa efetua o cálculo de um intervalo, com confiança de $90 \%$, possibilitando, assim, uma melhor avaliação do modelo. Quando se considera o limite mínimo do intervalo de confiança para a RMSEA, obtém-se a magnitude de 0,078 , possibilitando considerar a existência de um ajustamento aceitável do modelo hipotético.

Na realidade, conforme observaram Raykov e Marcoulides (2000), não existe um índice ideal que represente um critério definitivo para testar um modelo estrutural. Por esta razão, os autores recomendam que se empregue um conjunto selecionado de índices de bondade de ajustamento, embora inexista consenso entre todos (KLINE, 2005).

Embora a RMSEA não esteja exatamente no intervalo desejado, quando consideramos o conjunto de índices selecionados, é possível admitir um ajustamento global aceitável, cuja consistência fica substancialmente fortalecida com a significância das estimativas individuais dos parâmetros.

\section{Considerações finais}

A imagem corporativa representa a impressão total que se tem de uma empresa. Uma imagem favorável realça a experiência que se tem dela. Sendo assim, o presente trabalho desenvolveu uma escala que possibilita a avaliação da imagem corporativa das instituições privadas de ensino superior. 
Os resultados do estudo atestam que existe, de fato, escala que possibilita mensurar a imagem corporativa de instituições privadas de ensino superior. Essa escala é constituída por quatro variáveis latentes (construtos) que são determinadas por 25 variáveis observadas.

A utilização dessa escala é extremamente relevante quando se considera a necessidade crescente de se tomar decisões estratégicas consistentes com os objetivos de longo prazo, notadamente, o crescimento de participação da instituição no mercado de ensino superior privado.

Com efeito, hoje, no País, assiste-se a absorção de instituições privadas de ensino superior com imagens corporativas comprometidas ou fragilizadas por instituições que desfrutam não somente de sólida situação econômico-financeira, mas também de imagem corporativa reconhecida. Sendo assim, a imagem corporativa constitui um ativo de fundamental relevância para possibilitar a permanência de faculdades isoladas no mercado. É claro que, quando nos referimos ao crescimento, o investimento na solidez da imagem se torna ainda mais relevante, já que, nesse caso, a competição por ampliação da participação no mercado acontece entre instituições que desfrutam de imagens solidamente construídas.

$\mathrm{Na}$ medida em que a imagem corporativa é fundamental, é imprescindível, então, que seja administrada de forma a otimizar os resultados desejados. Para que seja administrada, a imagem precisa ser previamente conhecida. É nesse contexto que o presente estudo exibe a sua importância maior.

Entre as suas principais conclusões, convém destacar que os alunos dão ênfase para a formação da imagem corporativa de instituição privada de ensino superior e à sólida formação profissional, a qual necessita despertar o interesse de empresas conceituadas pelo recém-formado. $O$ fato de a instituição adaptar a sua grade curricular às mudanças também está fortemente relacionado à consistente imagem corporativa. 
Nesse contexto, fica clara a razão pela qual o fortalecimento da imagem corporativa se relaciona à adequação do conteúdo programático das disciplinas do curso à realidade, já que elas contribuem para a sólida formação profissional dos alunos.

Excelência acadêmica e capacidade didática do corpo docente também foram variáveis reputadas essenciais pelos respondentes na construção da imagem corporativa de instituições privadas de ensino superior.

Por último, no tocante à confiança que o aluno deposita na instituição, cabe destacar a sua crença quanto à capacidade da organização de se ajustar às mudanças ocorridas no mercado de trabalho.

Notamos, assim, que, se a trajetória profissional for considerada preocupação importante do aluno de faculdade isolada, seria recomendável que a instituição privada de ensino superior investisse na comunicação das ações empreendidas para uma sólida formação profissional do aluno, com a finalidade de fortalecer a sua imagem corporativa.

Face ao exposto, pode-se declarar que este estudo não apenas atesta a existência de escala de mensuração da imagem corporativa de uma instituição privada de ensino superior, como também aprofunda o conhecimento acerca dos nexos que estão presentes na avaliação institucional dos alunos e que fundamentam a construção de uma imagem sólida.

As limitações do estudo alicerçam sugestões para novos trabalhos. Inicialmente, é preciso ampliar a pesquisa para várias instituições privadas de ensino superior dos mais distintos bairros e municípios do Rio de Janeiro.

É preciso também considerar as diferenças regionais no País, pois é possível que a construção da imagem difira entre os alunos universitários de instituições privadas de ensino superior que atuam nas cidades das regiões Norte, Nordeste e Sul do Brasil. 
A escala também poderia ser aplicada à instituição pública de ensino superior, confrontando os resultados com aqueles obtidos a partir de sua utilização em instituição privada de ensino superior.

Ademais, existiria ganho de insight se fosse realizada investigação adicional para verificar as razões pelas quais a covariância entre as variáveis latentes "Qualidade das Instalações (Qualinst)" e "Confiança na Universidade (ConfUni)”, não apresentou significância estatística.

Além de pesquisas de natureza quantitativa, também é recomendável que sejam realizadas pesquisas qualitativa para que seja obtido um melhor ajuste da escala à instituição que se deseja estudar.

\section{Referências}

ARBUCKLE, J. L.; WOTHKE, W. Amos 4.0 user's guide. Chicago: SmallWaters, 1999.

BALMER, J. M. T.; GREYSER, S. A. Revealing the corporation: perpectives on identity, image, reputation and corporate-level marketing. London: Taylor \& Francis e-Library, 2003.

BOULDING, K. E. The image. Ann Arbor: University of Michigam Press, 1956.

BYRNE, B. M. Structural equation modeling with AMOS: basic concepts, applications and programming. New Jersey: Lawrence Erlbaum, 2001.

CIDADE, J. C. M.; CARVALHO, F. A. A.; VIEIRA, P. R. C. Imagem de um conselho profissional: estudo empírico sobre um caso brasileiro. Sociedade, Contabilidade e Gestão, Rio de Janeiro, v. 5, p. 24-39, 2010. Número especial.

DOWLING, G. R. Developing your company image into a corporate asset. Long Range Planning, Cambridge, v. 6, n. 2, p. 1-109, 1993.

FINK, A. How to sample in surveys. Thousand Oaks: Sage, 1995. 
FOMBRUN, C. Reputation: realizing value from the corporate image. Boston: Harvard Business School, 1996.

FOMBRUN, C.; PAN, M. Corporate reputations in China: how do consumers feel about companies? Corporate Reputation Review, New York, v. 9, n. 3, p. 165-170, 2006.

GAINES-ROSS, L. Reputation warfare. Harvard Business Review, Boston, p. 1-8, Dec. 2010. Disponível em: <http://www. webershandwick.com/uploads/news/files/WS_HBR_Reputation_ Warfare_Electronic.pdf>. Acesso em: 27. jun. 2014.

GRÖNROOS, C. Toward a third phase in service quality research: challenges and future directions. Advances in Services Marketing and Management, Bel Air, v. 2, n. 1, p. 49-64,1993.

HAIR JUNIOR, J. H. et al. Análise multivariada de dados. Porto Alegre: Bookman, 2009.

HERSTEIN, R.; MITKI, Y.; JAFFE, E. D. Corporate Image reinforcement in an era on terrorism. Corporate Reputation Review, New York, v. 11, n. 4, p. 360-370, 2008.

KAZOLEAS D.; KIM, Y.; MOFFITT, M. A. Institucional image: a case study. Corporate Communications: An International Journal, New York, v. 6 , n. 4 , p. 205-216, 2001.

KENNEDY, S.H. Nurturing corporate image: total communication or ego trip? European Journal of Marketing, Bingley, v. 11, n. 3, p. 120-164, 1977.

KLINE, R. B. Principles and pratices of structural equation modeling. New York: The Guilford Press, 2005.

KOTLER, P. Administração de marketing. São Paulo: Prentice Hall, 2000.

KOTLER, P.; ARMSTRONG, G. Princípios de marketing. São Paulo: Pearson, 2004. 
MARTINEAU, P. Sharper focus for the corporate image. Harvard Business Review, Boston, v. 36, n. 6, p. 49-58, Nov./Dec.1958.

MORGAN, J.; MINOR, D. CSR as reputation insurance primum non nocere. California Management Review, Berkeley, v. 53, n. 2, p. 40-59, 2011.

MOSCAROLA, J. Enquêtes et analyse de données. Paris: Vuibert, 1990.

PINSONNEAULT, A.; KRAEMER, S. L. Survey research in management information systems: an assessement. Journal of Managerment Information System, New York, v. 10, n. 2, p. 75-105, 1993.

RAYKOV, T.; MARCOULIDES, G. A. A first course in structural equation modeling. New Jersey: Lawrence Erbaum, 2000.

SILVA, J. M. C. Dimensões mais relevantes da qualidade percebida por parte dos alunos em serviços prestados por uma instituição de ensino superior: curso de medicina da UNIFESO. 2009. 113 f. Dissertação (Mestrado em Administração e Desenvolvimento Empresarial)Universidade Estácio de Sá, Rio de Janeiro, 2009.

SILVA, J. S. F. Modelagem de equações estruturais: apresentação de uma metodologia. 2006. 105 f. Dissertação (Mestrado em Engenharia de Produção)-Universidade Federal do Rio Grande do Sul, Porto Alegre, 2006.

SOUZA JUNIOR, E. C. A identidade organizacional e a imagem institucional do Exército Brasileiro. 2010. 164 f. Dissertação (Mestrado em Administração e Desenvolvimento Empresarial)-Universidade Estácio de Sá, Rio de Janeiro, 2010.

THEUS, K. T. Academic reputations: the process of formation and delay. Public Relations Review, Maryland, v. 19, n. 3, p. 277-291, 1993.

VENDELO, M. T. Narrating Corporate Reputation. International Studies of Management \& Organizations, New York, v. 28, n. 3, p. 120, 1998. 
VIEIRA, P. R. C.; FREITAS, J. A. S. B. Transparências e imagem institucional: o caso do Banco Central do Brasil. Revista Eletrônica Gestão e Sociedade, Ed. 1, ago. 2007. Disponível:<http:// gestaoesociedade.org/gestaoesociedade/article/view/545>. Acesso em: 27 jun. 2014.

VIEIRA, P. R. C.; RIBAS, J. R. Análise Multivariada com uso do SPSS. Rio de Janeiro: Ciência Moderna, 2011.

VIEIRA, P. R. C.; TROCCOLI, I. R.; SILVA, J. M. C. A relevância do corpo docente na qualidade percebida em serviço de ensino superior no Brasil: um estudo com modelagem de equações estruturais. Revista Economia \& Gestão, Belo Horizonte, v. 11, n. 26, p. 82-109, maio/ago. 2011.

Artigo recebido em: 31/05/2013

Aprovado em: 26/11/13 